\title{
A New Diagnosis of Addison's Disease with a Twist
}

\author{
Majed Alhabib ${ }^{1 *}$, Karen McAssey ${ }^{2}$, and Melissa Parker ${ }^{3}$ \\ ${ }^{1}$ Pediatric Endocrinology Fellow, McMaster Children's Hospital, Hamilton, Canada \\ ${ }^{2}$ Department of Pediatric, McMaster Children's Hospital, Hamilton, Canada \\ ${ }^{3}$ Department of Pediatric, McMaster Children's Hospital, Hamilton, Canada
}

\begin{abstract}
Received: August 22, 2016; Accepted: September 23, 2016; Published: September 26, 2016
*Corresponding author: Majed Alhabib, Pediatric Endocrinology Fellow, McMaster Children's Hospital, Hamilton, Canada, E-mail: drmajedus105@yahoo.com
\end{abstract}

\begin{abstract}
Addison's disease is a rare autoimmune endocrine disorder. It affects the cortex of the adrenal glands causing cortisol, aldosterone and adrenal androgen deficiencies. Addison's disease usually presents with non specific symptoms. As a result, the diagnosis can be difficult and delayed. We report a case of a 17 year old male presenting to our emergency department with abdominal pain, vomiting, hypotension, and clinical stigmata suggestive of Addison's disease. Blood work identified hyponatremia and hyperkalemia. The diagnosis of Addison's disease was confirmed by hormonal investigations. This young man's clinical course was characterized by a secondary decompensation, which necessitated review of his presentation and possible complicating features.
\end{abstract}

\section{Case Report}

A 17 year old male presented to the Pediatric Emergency Department (PED) with a 5 day history of fatigue, vomiting and abdominal pain. He attended the PED on two prior occasions in the preceding 2 years with similar findings. On these occasions, he was found to be having hyponatremia, which corrected with intravenous normal saline, and urine toxicology screens were positive for cannabis. He was discharged from the PED within 24 hours.

This young man reported good health apart from these two PED visits. He was systemically well, with no history of salt craving, symptoms of hypoglycemia, or episodes of presyncope or syncope. Family history was negative for endocrine or autoimmune disorders.

On physical examination he looked unwell, but was conscious, alert and oriented. Vital signs included a temperature $37^{\circ} \mathrm{C}$, respiratory rate 24 breaths/ minute, and heart rate 113 beats/ minute. He was hypotensive with a blood pressure of $83 / 52$ mmHg. His body mass index was 19 kilograms/meter square. Hyper pigmentation was present over his total body as shown in Figure 1. The remainder of his physical examination was unremarkable.
Laboratory investigations revealed a blood glucose of 2.3 mmol/ l (normal 3.8-7.7 mmol/ l), sodium $115 \mathrm{mmol} / \mathrm{l}$ (normal $135-145 \mathrm{mmol} / \mathrm{l}$ ) and potassium $5.1 \mathrm{mmol} / \mathrm{l}$ (normal 3.5-5 $\mathrm{mmol} / \mathrm{l}$ ). Complete blood count showed white blood cells $5.4 \mathrm{x}$ $10^{9}$ cells / liter, red blood cells $4.45 \times 10^{12}$ cells / liter and platelets $194 \times 10^{9}$ cells/ liter. His urine electrolytes were sodium 90 $\mathrm{mmol} / \mathrm{l}$ and potassium $19 \mathrm{mmol} / \mathrm{l}$. Urine toxicology was positive for cannabis and opiates. Serum cortisol was unmeasurable at less than $28 \mathrm{nmol} / \mathrm{l}$ and ACTH level was elevated at more than $278 \mathrm{pmol} / \mathrm{l}$ (normal < $10.3 \mathrm{pmol} / \mathrm{l}$ ). Renin level was high at 1393 $\mathrm{ng} / \mathrm{l}$ (normal 3.3-61 ng/ l) and the aldosterone level was less than $35 \mathrm{pmol} / \mathrm{l}$ (normal 55-638 pmol/ l).

Initially, he was managed with a bolus of normal saline 20 milliliter/ kilogram and given intravenous (IV) hydrocortisone 100 milligrams. Subsequent treatment included hydrocortisone 25 milligrams IV every 6 hours and IV D5W/NS at 100 milliliters/ hour. Electrolyte disturbances corrected after 48 hours.

Seventy-two hours after admission, he developed new onset fever of $39.1^{\circ} \mathrm{C}$, cough, and a recurrence of hypotension with a blood pressure at 78/37 $\mathrm{mmHg}$ and tachycardia with a heart rate 113 beats/minute. Intravascular fluid resuscitation was initiated, broad spectrum antibiotics were administered, and the Pediatric

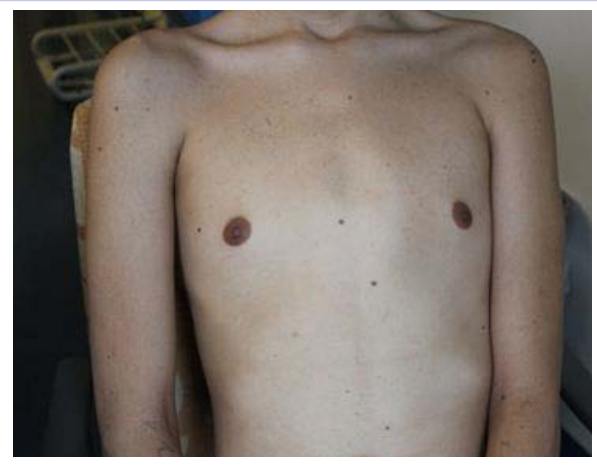

Figure 1: hyperpigmentation over the chest, abdomen and arms 
Intensive Care Unit was consulted. Adequacy of hormonal replacement was confirmed, a stress dose of hydrocortisone was administered, and a diagnosis of septic shock was suspected. Chest X-Ray (CXR) at the time of initial presentation had been negative, but a repeat CXR performed at the time of deterioration revealed a right lower lobe round pneumonia (Figure 2). Blood work showed white blood cells of $15 \times 10^{9}$ cells/ liter, neutrophils $12.9 \times 10^{9}$ cells/ liter, lymphocytes $1.4 \times 10^{9}$ cells / liter , red blood cells $3.28 \times 10^{12}$ cells / liter and platelets $171 \times 10^{9}$ cells/ liter. The patient was treated with levofloxacin for a total of 10 days due to a penicillin allergy. His fever resolved after 24 hours and blood culture was negative.

This young man was discharged from hospital in good health 7 days following his initial presentation. His discharge medications included 500 milligrams of levofloxacin daily to complete a 10 day course, fludrocortisones 0.1 milligram daily, and dexamethasone 1 milligram daily. He was well when seen in endocrinology clinic one month following discharge, with blood work demonstrating electrolytes within the normal range, ACTH level normalized to $2 \mathrm{pmol} / \mathrm{l}$ and renin $27.2 \mathrm{ng} / \mathrm{l}$.

\section{Discussion}

Addison's disease is a rare autoimmune endocrine disorder and the diagnosis can be easily overlooked. Hyper pigmentation and electrolyte disturbances can be a clue to the diagnosis. Abdominal pain and vomiting can be associated with an Addison a crisis and with lower lobe pneumonia. In the case presented, the radiological evidence of pneumonia lagged behind the

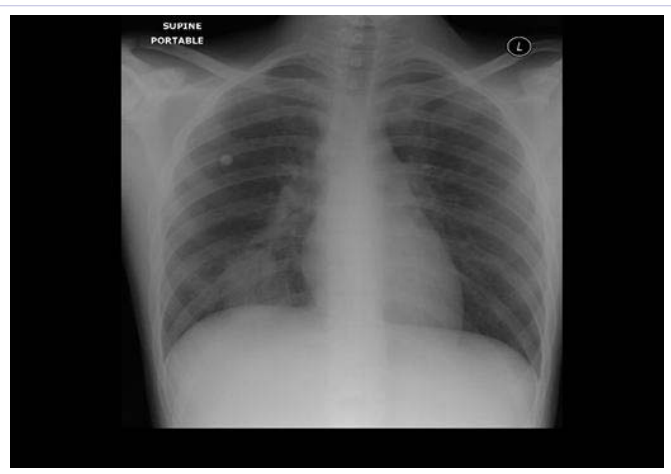

Figure 2: Right lower lobe round pneumonia. clinical course. In retrospect, the patient's initial presentation of abdominal pain and vomiting was classic for a lower lobe pneumonia.

Community acquired pneumonia is caused by typical pathogens such as streptococcus pneumoniae, Haemophilus influenzae and Moraxella catarrhalis or atypical pathogens including staphylococcus aureus, klebsiella pneumoniae and pseudomonas aeruginosa. The typical pathogens cause mainly respiratory symptoms while the atypical pathogens cause respiratory and gastrointestinal symptoms. Round pneumonia is defined as a chest infection presenting as a lesion in the chest $\mathrm{x}$-ray with a round shape. It is more common in children than adults and the cause is bacterial.

Community acquired pneumonia is an important precipitating cause of an adrenal crisis. Our literature review revealed case reports of other individuals recognized to have an adrenal crisis precipitated by an infection [1-3]. Importantly, after thorough review of the literature, this case report represents the second pediatric patient reported to have initial presentation of Addison's disease identified by an adrenal crisis secondary to pneumonia [1].

\section{Conclusions}

Consider adrenal insufficiency in a hyper pigmented individual and determine serum electrolytes urgently. Community acquired pneumonia is an important precipitating cause of an adrenal crisis.

For patients in shock with a known adrenal insufficiency, it is important to consider both endocrine and non-endocrine causes in the differential diagnosis.

\section{References}

1. Thomas M. Pneumocystis Carinii Pneumonia in 15-Year-Old with Chronic Mucocutaneous Candidiasis. Scand J Infect Dis. 1999;31(2):203-206.

2. Milenkovic A, Markovic D, Zdravkovic D, Peric T, Milenkovic T, Vukovic R. Adrenal crisis provoked by dental infection: case report and review of the literature. Oral Surg Oral Med Oral Pathol Oral Radiol Endod. 2010;110:325-329.

3. Akin L, Kurtoglu S, Kendirci M, Akin MA, Kardas F. Primary Adrenal failure due to viral infection in an infant. Eur J Pediatr. 2010;169(7):887-9. doi: 10.1007/s00431-009-1103-0. 